\title{
Six Years After the Closure of the OPGs and the Establishment of REMS: Considerations and Future Perspectives
}

\author{
Fulvio Carabellese ${ }^{1} \&$ Felice Carabellese $^{2}$ \\ ${ }^{1}$ Department of Medical Sciences, Surgery and Neurosciences, University of Siena, Italy \\ ${ }^{2}$ Department of Interdisciplinary Medicine, Criminology and Forensic Psychiatry Section, University of Bari, Italy
}

Submission: December 13, 2020; Published: February 08, 2021

*Corresponding author: Fulvio Carabellese, Department of Medical Sciences, Surgery and Neurosciences, University of Siena, Italy

Keywords: Psychotherapy; Psychiatric disorder; REMS; Oral antipsychotics; Psychiatry evaluation; Clinical risk assessments; Rehabilitation;

Treatment strategies; Risk management.

\section{Editorial}

The law of 30 May 2014, n. 81 represents the point of arrival of an important reform of the Italian psychiatric forensic system. With it, in fact, Italy passed from a forensic psychiatric model based on OPGs to one based on REMS. The first OPG (Ospedale Psichiatrico Giudiziario, High Security Hospital), was established in Italy in 1872 in Aversa, in Southern Italy to place those offenders recognized as "not guilty by reason of insanity" at the time of committing the crime [1]. At that time, the OPGs were still called MG (Manicomio Giudiziario) and only with the law n. 354/1975 their name was changed. The OPGs were basically Italy's maximum security hospitals and their model of care remained unchanged until the DPCM (Decree of the President of the Council of Ministers) of April 1, 2008, when the responsibility for treating OPG inpatients and mentally ill prisoners was transferred from the Department of Justice to the Department of Health. With the same decree, the government recommended for the first time in more than a century the overcoming of the OPGs, finally implemented seven years later with the aforementioned law 81 of 2014.

After that law, the six existing OPGs have been closed and substituted by an alternative network of residential care facilities called REMS - Residencies for Execution of Security Measures. During their closing, while inpatients were progressively transferred to the REMS, the OPGs continued to operate but they have not accepted any new patients since their final closure was set for April 1, 2015. The total number of patients confined in the OPGs by June 30, 2010 amounted to 1,457 men and 95 women (Ministry of Health); at the end of 2014 there were 672 inpatients in the 6 OPGs. It took almost two years to complete the discharge of all the remaining patients from OPGs [2]. The structural and functional characteristics of the REMS are aimed at assuring general security, individual care, rehabilitation programs in community environment and small scale dimensions [3]. In fact, the law established that each REMS consists of residential structures capable of accommodating a maximum of 20 patients assisted by health professionals 24 hours a day. The law also wanted to ensure that the presence of these structures covered the entire national territory, providing that each of the 20 Italian regions had at least one REMS. To date, thirty one REMSs are active in Italy, for a total of up to 600 beds reserved only to the offenders whose criminal responsibility is totally excluded or reduced due to a serious mental illness at the time of the crime, socially dangerous, according to the Italian legislation (art. 203 Penal Code). Internment in REMS is designed as a custodial security measure which is "extreme and exceptional" and in any case Law 81 of 2014 limits the maximum duration of internment in REMS to the maximum time of imprisonment had the offender been found guilty of the crime and sentenced.

The exceptional nature of the REMS security measure derives from the intention of the Italian legislator to balance two different principles of equal dignity. On the one hand, in fact, there is the principle of patient consent which consists in the voluntary nature of the medical treatment already recognized for non-forensic patiens by Law 180 of 1978 . On the other hand, there is the need to contain patients who have committed offenses with restrictive measures because of their recognized social dangerousness. By 
balancing the two colliding requirements, the legislator intended to give the REMS internment the character of "last resort". In fact, with Law 81 of 2014, it was established that the judge will have to opt for lighter security measures (such as "libertà vigilata, sort of probation) whenever the social dangerousness of the patient who is the offender can be managed and contained in general community facility.

A study by Catanesi and colleagues [4] on REMSs conducted in 2019 showed that the $89 \%$ of the patients were male and the most frequently diagnosed psychiatric disorder in REMS patients was schizophrenia (33.0\%), followed by personality (32.0\%) and substance-related disorders $(21.4 \%)$. The same study reported that most of the patients $(81,2 \%)$ are involved in rehabilitation programs; almost a quarter of patients $(23,3 \%)$ receive more than one type of psychotherapy and almost a fifth (19.3\%), psychoeducational programs. The most frequent drug therapies prescribed are oral antipsychotics (79\% of total sample); acting injectable (LAI) preparation (47\% of total sample); mood stabilizers $(47.5 \%)$, such as carbamazepine, lithium carbonate, or sodium valproate, were co-administered to patients receiving a LAI or with oral antipsychotics too. Observing the main characteristics of the REMS, it appears more clearly that they were designed to overcome the problems that affected the previous OPG system: inadequate treatment provided, the presence of police officers and the possibility of indefinite hospitalization, due to prison buildings characterized by a restrictive architecture.

Although many of these critical issues have been addressed by the reform that led to the establishment of REMS, six years after their introduction, new problems can also be highlighted. Some critical issues that emerged are due to the absence of specific regulations set ad hoc on the equally specific area of intervention affected by the law. The definitive overcoming of the OPGs by the Law n. 81 of 2014 took place, in fact, completely unrelated to the Criminal Code, the Criminal Procedure Code and the Penitentiary Law, which remained unchanged [5]. The consequent birth of the REMS has entailed many problems of interpretation given that the REMS differ from the OPG for the presence of an almost full sanitization of these structures. The management of the REMS, in fact has been entrusted exclusively to health professionals, while in the OPGs the custodial management belonged to the penitentiary administration. In this way, a distinction has been made by law between the health aspect and the prison aspect. At the moment, however, due to a lack of coordination of the REMS instituting law with the other areas of the aforementioned legal system, it is not clear whether and to what extent the custodial management and application of the penitentiary system in REMS falls on psychiatrists.

Other issues emerged referring to the need for greater homogeneity. In Italy, each region decides autonomously on health matters and this has led to a great heterogeneity in the practices adopted in the individual regional realities. This can cause problems with the compliance of the principle of territoriality according to which people must be hosted in the forensic facilities present in the regions of origin. For last, the saturation of the structures, considering that the approximately 600 beds made available by all the REMSs represent less than half of the total beds of the six OPGs before their closure. A limited availability of places in REMSs has led, in fact, to the creation of a "waiting list" for admissions. In addition to this and the already difficult management of waiting lists, there is an increasing risk of the measure in REMS being ineffective due to the large presence in it of people subjected to temporary security measures. Despite the legislator's intentions to use REMS only as a last resort and to privilege the "libertà vigilata", where possible, many prosecutors continue to apply internment in REMS as a provisional security measure, with a consequent detriment of the therapeutic potential of the same, both against subjects who at the end of the process may be subjected to an ordinary prison sentence outside the forensic structures, both of patients already present in REMS in a definitive manner, given the greater number of subjects in need of treatment at the same time.

An important point is that these lists are managed directly by the Ministry of Justice without the use of admission priority criteria based on clinical risk assessments [6] and doubts were raised regarding the criteria that it must consider ascertaining the dangerousness of the perpetrator, suffering from a mental illness, in order to decide whether to apply, or even just continue, the security measure. If, on the one hand, the introduction of the maximum duration of the security measure of detention is in line with the principles of legal civilization, on the other hand, it should be counterbalanced in light of the absence of certainty criteria in the psychiatric-forensic assessment of the social dangerousness. Overall, REMS structures appear undersized not only for the capacity of beds but also for the number of staff who often find themselves having to deal with aggressive patients, difficult to treat and complicated in their management, also in terms of safety and security. For these reasons, the closure of OPGs has created a duty to adopt evidence-based strategies for assessing the risk of violence that are functional to the development of risk management and treatment strategies [3].

Once again, it is right to specify that the Italian psychiatric system has always been in many ways very peculiar at an international level. With the law 833 of 1978, Italy decree for the first time the closure of the OPs (Psychiatric Hospitals) and provided for the transition to a community treatment model. Later on, as we saw, Italy closed also the OPGs in 2014. During the years following these important changes in the psychiatric patient care system, Italian psychiatrists have acquired specialized skills that characterize the operational practices to which they apply, often different from other European countries. Some of the strengths of the current Italian mental health care model include the widespread public outpatient psychiatric services throughout 
the country, interventions by the family and social environment and attention to other protective prognostic factors [7].

After the closure of OP, however, Italian general psychiatrists did not manage the violent and criminal behavior of their patients, which had previously been the responsibility of the Judicial System and its OPGs, so the National Health System psychiatrists gradually came to completely neglect these issues. Therefore, clinical psychiatrists, after OPGs closure, have to manage the risk of violence. It is the authors' opinion that the use in Italian psychiatrist's clinical practice of use of assessment and management tools, including those for the risk of violent acts is desirable in the near future for different reasons. At first, begin to use them habitually and regularly, as it should be, especially in our REMSs, in our forensic but in non-forensic facilities too would have the undoubted advantage of allowing us to compare ourselves with the models of other countries. Our forensic model of treatment is very unusual indeed, so the use of such tools would provide more objective data with which to support statements that today may appear self-referential. Hopefully, in few years, maybe, we will be able to demonstrate that our approach to the care of mentally ill patients it is no less effective than those chosen from countries other than ours and surely more ethical. From a practical perspective, these instruments can also guide the decision makers with the choice of priority criteria in accessing the waiting lists for admission to REMS. Finally, we think that the clinical and professional experience remains fundamental, but the use of these tools can be of valid comfort to the diagnostic and clinical reasoning both in the practice of general psychiatry and in forensic psychiatry evaluation as it can provide a unique, easyto-share clinical-anamnestic and historical information base that functions as a common source of reflection for all.

\section{References}

1. Carabellese F, Felthous AR (2016) Closing Italian Forensic Psychiatry Hospitals in Favor of Treating Insanity Acquittees in the Community. Behavioral Sciences \& the Law 34(2-3): 444-459.

2. Rossetto I, Franconi F, Felthous AR, Carabellese Fu, Di Vella G, et al. (in press) Differences between readmitted and non-readmitted men who were discharged from Italian forensic units: A retrospective study.

3. Castelletti L, Scarpa F, Carabellese F (2018) Treating not guilty by reason of insanity and socially dangerous subjects by community psychiatric services: An Italian perspective. Italian Journal of Criminology 12(3): 182-189.

4. Catanesi R, Mandarelli G, Ferracuti S, Valerio A, Carabellese F (2019) The new Residential Forensic Psychiatric System (REMS): A one-year population study. Italian Journal of Criminology, Special issue 7-23.

5. Mandarelli G, Coluccia A, Urbano MT, Carabellese F, Carabellese F (2019) Current issues, penitentiary treatment problems and prospect after law 81/2014. Italian Journal of Criminology 13(4): 316-26.

6. Carabellese F (2017) Closing OPG: Socially dangerous mentally ill offenders' diagnostic tools. from forensic-psychiatric evaluation to the treatment. Italian Journal of Criminology 3: 173-181.

7. Carabellese F, Candelli C, La Tegola D, Rocca G, Martinelli, D. \& Catanesi, R. (2015) Violent behavior in cohort of psychiatric patients: psychosocial risk and protective factors. Italian Journal of Criminology 2: 157162.

\section{Your next submission with Juniper Publishers will reach you the below assets}

- Quality Editorial service

- Swift Peer Review

- Reprints availability

- E-prints Service

- Manuscript Podcast for convenient understanding

- Global attainment for your research

- Manuscript accessibility in different formats

( Pdf, E-pub, Full Text, Audio)

- Unceasing customer service

Track the below URL for one-step submission https://juniperpublishers.com/online-submission.php 